\title{
Infant and Young Child Feeding (IYCF) Practices by Rural Mothers of Bangladesh
}

\author{
Md. Saizuddin', Md. Shaidul Hasan² \\ ${ }^{1}$ Professor, Department of Community Medicine, Z. H. Sikder Women's Medical College \& \\ Hospital, Dhaka, Bangladesh; ${ }^{2}$ Register, Department of Medicine, Z. H. Sikder Women's \\ Medical College \& Hospital, Dhaka, Bangladesh
}

[Received: January 2015; Revised: March 2015; Accepted: June 2015; Published: January 2016]

\begin{abstract}
Background: Infant and young child feeding (IYCF) practices play vital role for the growth \& development in the early months of life. Objective: The purpose of the present study was to determine and to identify the patterns and influencing factors of feeding practices in infant and young children of 0-2 years old in Bangladesh. Methodology: A descriptive type of cross sectional study was carried out to assess the pattern of infant \& young child feeding practices by the rural mothers of Bangladesh with a sample size of 450 during the months of January to December of 2015 . Result: Out of 450 children, $51.1 \%$ are female \& $48.9 \%$ are male. The proportions of infants with early initiation of breastfeeding $(13.6 \%)$ and exclusive breastfeeding fewer than six months (57.3\%) and infants who received complementary feeding at the age of 6-8 months $(55.7 \%)$ were low. It showed that $90.4 \%$ of mothers have knowledge on exclusive breast feeding but only $57.3 \%$ of them have practiced it for $4-6$ months. It further revealed that only $8.4 \%$ of mothers \& $13.6 \%$ of fathers were illiterate. The main problems revealed from the study were late initiation of breastfeeding, low rates of exclusive breastfeeding, and inappropriate complementary feeding practices. It further revealed that $69.3 \%$ of the respondents had two or less children and $30.7 \%$ had three or more children. Conclusion: Majority of the respondents have the knowledge on complementary feeding, knowledge on preparation of complementary feeding, knowledge on preparation of food by grains, knowledge on preparation of food by milk and milk products and knowledge on preparation of food by meat, fish, poultry, liver. [Journal of National Institute of Neurosciences Bangladesh, 2016;2(1): 19-25]
\end{abstract}

Keywords: Breastfeeding; child-feeding practices; cross-sectional studies; descriptive studies; exclusive breast feeding; infant-feeding practices; complimentary feeding

Correspondence: Prof. Dr. Md. Saizuddin, Professor, Department of Community Medicine, Z. H. Sikder Women's Medical College \& Hospital, Dhanmondi, Dhaka, Bangladesh; Email: drsaizuddin@yahoo.com; Cell no.: +8801712031610

Conflict of interest: There is no conflict of interest to any of the authors of this article.

Funding agency: This research work was performed by own cost. There was funding agency had given the support.

Contribution to authors: MS \& MSH were contributed from protocol preparation, report writing, preparation of the manuscript as well as the revision of the manuscript.

How to cite this article: Saizuddin M, Hasan MS. Infant and Young Child Feeding (IYCF) Practices by Rural Mothers of Bangladesh. J Natl Inst Neurosci Bangladesh, 2016;2(1): 19-25

Copyright: (C2016 Saizuddin and Hasan. Published by Journal of National Institute of Neurosciences Bangladesh. This article is published under the Creative Commons CC BY-NC License (https://creativecommons.org/licenses/by-nc/4.0/). This license permits use, distribution and reproduction in any medium, provided the original work is properly cited, and is not used for commercial purposes.

\section{Introduction}

Infant and young child feeding (IYCF) practice comprises by breastfeeding as well as complementary feeding, it has major role in determining the nutritional status of children. Poor feeding practices in infancy and early childhood results in malnutrition contribute to impaired cognitive and social development, poor school performance and reduce productivity in later life. 
Malnutrition has been responsible, directly or indirectly for $67 \%$ of all deaths among children less than 5 years of age in India ${ }^{1}$. Breastfeeding aspects, the dietary diversity and diet frequency aspects all together reduce the mortality and morbidity of young children from malnutrition.

Bangladesh, with about 340,000 childhood deaths per year, ranks number seven in the world along with other countries: India, Nigeria, China, Pakistan, DR Congo, Ethiopia, Afghanistan, Tanzania, and Indonesia are in the list of 10 countries with the most number of childhood deaths ${ }^{2}$. In Bangladesh, infant mortality has continued a notable decline but it is still high compared to developed countries. Reducing infant mortality is both an ethical obligation and a pre-requisite to achieve the Sustainable development goals (MDG-4). The important reasons for high infant mortality rate in Bangladesh are the diarrheal diseases, respiratory infection, low birth weight, congenital anomaly and malnutrition and also related with limited use of healthcare services, availability of public health facilities, family planning services and community factors ${ }^{2}$. At the community level, infant mortality might be influenced by specific cultures and customs, by geographical aspects such as climate and soil fertility and by the quantity and quality of infrastructure. Infants aged (0-5 months) who are not breastfed have 7-fold and 5-fold increased risks of death from diarrhea and pneumonia, respectively, compared with infants who are exclusively breastfed ${ }^{3-4}$. At the same age, nonexclusive rather than exclusive breastfeeding results in more than 2-fold increased risks of dying from diarrhea or pneumonia 5 .

There are many wrong practices and perceptions prevailed among different socio-demographic groups. In Bangladesh, initiation of breast feeding immediately after birth proceeded by so called pre-lacteal/heating food feeds. About 98\% new born are traditionally fed "heating foods" such as honey, sweeten water, or mustard oil with believe that these foods give strength and prevent colds during first few days of life and they also believed that pre-lacteal feed makes baby's voice sweet ${ }^{6}$. During first six months of life, breast milk should be fed alone and from then onwards it should be complemented with other sources of nutrition until at least 2 years of age ${ }^{7-8}$. In Bangladesh, two main reasons for stopping breastfeeding were observed which are insufficient breast milk and baby refusing the breast ${ }^{9}$. And other causes of poor breastfeeding rates in Bangladesh are lack of support for mothers to initiate and sustain breastfeeding and secondly the erosion made by breast milk substitutes companies. WHO offers three recommendations for IYCF practices for children aged 6-23 months which are continued breastfeeding or feeding with appropriate calcium-richen foods if not breastfed, feeding solid or semi-solid food for a minimum number of times per day according to age and breastfeeding status and including foods from a minimum number of food groups per day according to breastfeeding status ${ }^{10}$. The present study was therefore undertaken to determine and to identify the patterns and influencing factors of feeding practices in infant and young children of $0-2$ years old in Bangladesh.

\section{Methodology}

This descriptive type of cross sectional study was conducted in 45 EPI Centers of ten upazilas of Dhaka, Gazipur, Kishoregonj, Feni and Chandpur districts. The study period was from January to December, 2015 for a period of one (01) year. Samples were collected by using purposive sampling technique to explore pattern of Infant and Young Child Feeding Practices by the rural mothers. The mothers of children (aged 0-23 months) attending at EPI centers for immunization were included in this study. Data were collected by trained volunteers regarding IYCF perceptions and practices by interviewing the mothers using pre-designed, pre-tested, semi-structured interviewer administered questionnaire in Bengali, the local language, based on local culture and customs. Only the mothers of children less than 24 (0-23) months were included in the study after obtaining verbal informed consent. The different variables considered were socio-demographic characteristics like age and sex of the child; age, literacy status, occupation and parity of the mothers; family type, per capita income (PCI) and type of perception and practice like timing of breastfeeding initiation, colostrums feeding, pre-lacteal feeds, duration of exclusive breastfeeding, bottle-feeding, complimentary feeding etc. Statistical analysis was performed by using Statistical Package for Social Science (SPSS) version 21.0 for Windows. Quantitative variables were expressed as mean and standard deviation. Categorical variables were expressed as proportions and percentage.

\section{Results}

This descriptive type of cross sectional study was carried out to assess the prevalence of Infant \& Young Child Feeding Practices by the rural mothers of Bangladesh with a sample size of 450 . 
Table 1: Distribution of the Baby by Age $(n=450)$

\begin{tabular}{lcc}
\hline Age of Baby & Frequency & Percentage \\
\hline Less than 6 months & 99 & 22.0 \\
6 to 12 months & 164 & 36.4 \\
13 to 24 months & 187 & 41.6 \\
\hline Total & $\mathbf{4 5 0}$ & $\mathbf{1 0 0 . 0}$ \\
\hline
\end{tabular}

In this study $41.6 \%$ of the baby was in 13 to 24 months followed by $36.4 \%$ in 6 to 12 months and $22.0 \%$ in less than 6 months (Table 1). .

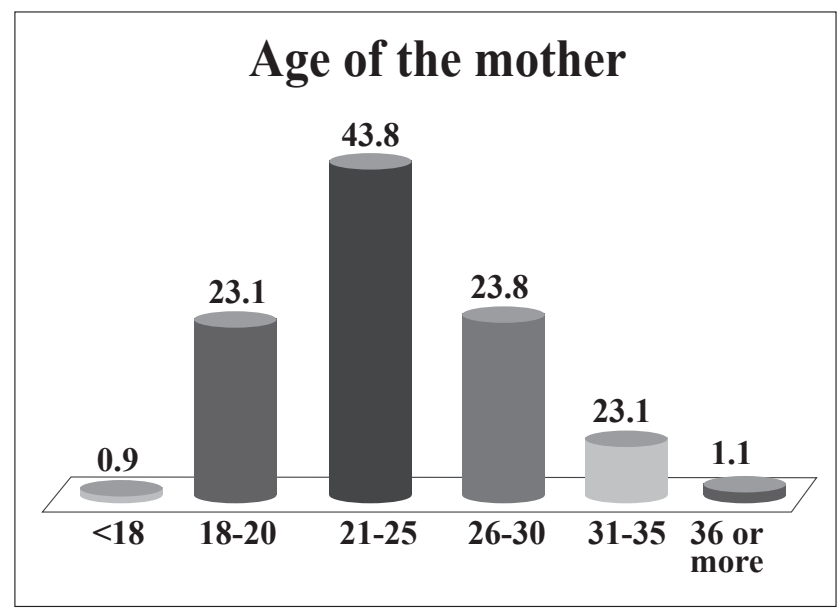

Figure I: Distribution of the mothers by age

In this present study $23.1 \%$ of mothers was in $18-20$ years of age group, followed by $43.8 \%$ was in 21 to 25 years, $23.8 \%$ in $26-30$ years, $7.3 \%$ was in $31-35$ years, respectively (Figure I).

Table 2: Distribution of the Parents by Educational Status $(\mathrm{n}=450)$

\begin{tabular}{lcc}
\hline Educational status & Mother & Father \\
\hline Illiterate & $38(8.4 \%)$ & $61(13.6 \%)$ \\
class v or less & $84(18.7 \%)$ & $122(27.1 \%)$ \\
Class vi -- x & $211(46.9 \%)$ & $190(42.2 \%)$ \\
SSC pass or more & $117(26.0 \%)$ & $77(17.1 \%)$ \\
\hline Total & $\mathbf{4 5 0}$ & $\mathbf{4 5 0}$ \\
\hline
\end{tabular}

In this study $26 \%$ of mothers \& $17.1 \%$ of fathers are SSC pass or more respectively, on the other hand, only $8.4 \%$ of mothers \& $13.6 \%$ of fathers are illiterate (Table 2).

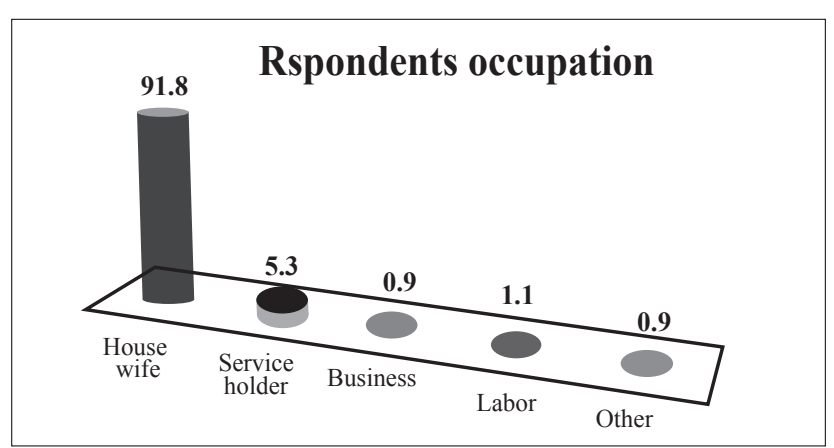

Figure II: Distribution of the Respondents by Occupation
Majority of the respondents $(91.8 \%)$ was housewife and only $5.3 \%$ was service holder (Figure II).

Table 3: Distribution of the Fathers as Occupation $(\mathrm{n}=450)$

\begin{tabular}{lcc}
\hline Husbands Occupation & Frequency & Percentage \\
\hline Farming & 150 & 33.3 \\
Service holder & 85 & 18.9 \\
Business & 123 & 27.3 \\
Labor & 39 & 8.7 \\
Other & 53 & 11.8 \\
\hline Total & $\mathbf{4 5 0}$ & $\mathbf{1 0 0 . 0}$ \\
\hline
\end{tabular}

One third $(33.3 \%)$ of the respondents' husbands are farmer, $27.3 \%$ are businessman, $18.9 \%$ was service holder and only $8.7 \%$ was labor (Table 3 ).

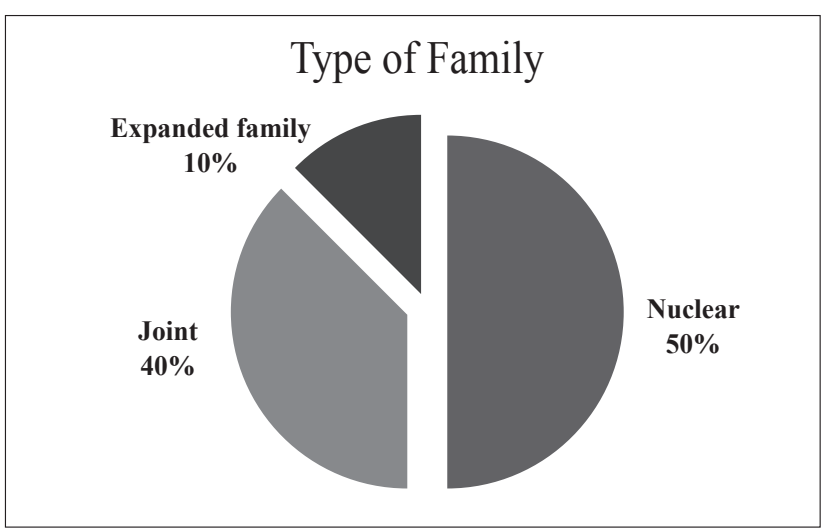

Figure III: Distribution of the Respondents by Type of Family

Half of the respondents $(50.0 \%)$ belongs to nuclear family, $40.4 \%$ in joint family and $9.6 \%$ lived in expanded family (Figure III).

Table 4: Distribution of the Respondents by Family Size $(\mathrm{n}=450)$

\begin{tabular}{lcc}
\hline Family size & Frequency & Percentage \\
\hline 3 or less members & 75 & 16.7 \\
4 - 6 members & 269 & 59.8 \\
7 -- 9 members & 85 & 18.9 \\
10 or more members & 21 & 4.7 \\
\hline Total & $\mathbf{4 5 0}$ & $\mathbf{1 0 0 . 0}$ \\
\hline
\end{tabular}

In this study $16.7 \%$ of the respondents belonged to the family consisting of 3 or less members, \& only $4.7 \%$ belonged to the family members of 10 or more (Table 4 ). 


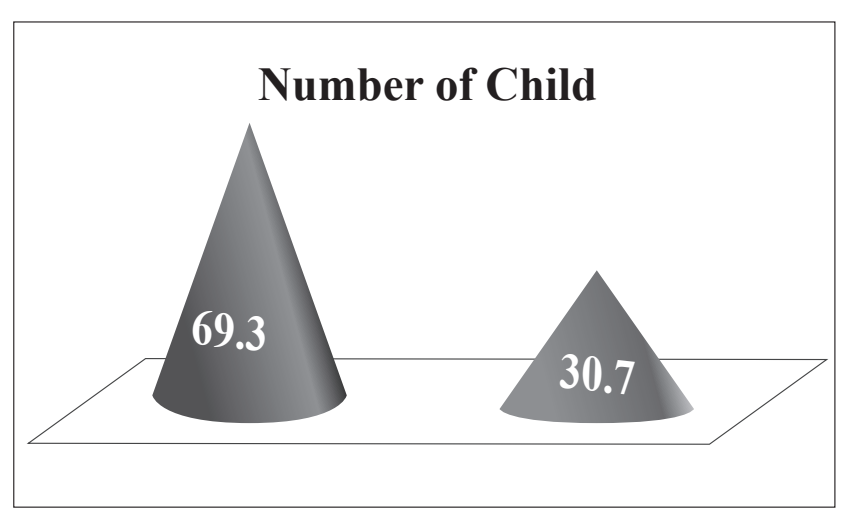

Figure IV: Distribution of the respondents by number of children

In this study $69.3 \%$ of the respondents have two or less children and $30.7 \%$ have three or more children (Figure IV).

Table 5: Distribution of the Respondents by Monthly Family Income $(\mathrm{n}=450)$

\begin{tabular}{lcc}
\hline Monthly income (TK) & Frequency & Percentage \\
\hline$<5,000$ & 150 & 33.3 \\
$5,001-10,000$ & 162 & 31.3 \\
$10,001-15,000$ & 142 & 14.9 \\
$15,001->20,000$ & 46 & 10.2 \\
\hline Total & $\mathbf{4 5 0}$ & $\mathbf{1 0 0 . 0}$ \\
\hline
\end{tabular}

In this study $33.3 \%$ off the respondents monthly family income was BDT $\leq 5000,31.3 \%$ was $5001-10000.14 .9 \%$ was $10001-15,000$ and $10.2 \%$ was 15001 to $\geq 20000$ (Table 5).

Table 6: Distribution of the Children by Gender $(n=450)$

\begin{tabular}{lcc}
\hline Gender of child & Frequency & Percentage \\
\hline Boy & 220 & 48.9 \\
Girl & 230 & 51.1 \\
\hline Total & $\mathbf{4 5 0}$ & $\mathbf{1 0 0 . 0}$ \\
\hline
\end{tabular}

In this study $51.1 \%$ of the children was girl and $48.9 \%$ was boy (Table 6).

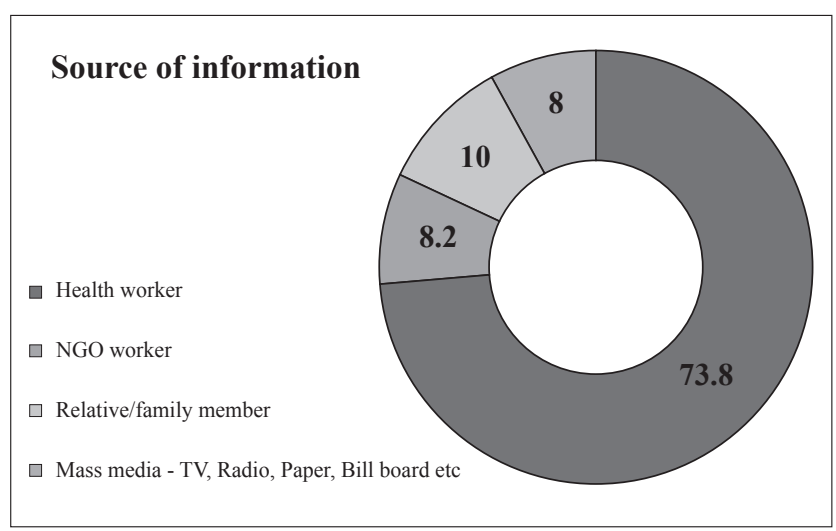

Figure VI: Distribution of the Respondents by Source of Information
In this study $73.8 \%$ of the respondents' got information from health workers followed by $10 \%, 8.2 \%$ and $8 \%$ from relative/family members, $\mathrm{NGO}$ workers and mass media respectively (Figure VI).

Table 7: Distribution of the respondents by Knowledge \& Practices on colostrums $(n=450)$

\begin{tabular}{lccc}
\hline Colostrums & Yes & No & Total \\
\hline Knowledge & $426(94.7 \%)$ & $24(5.3 \%)$ & $450(100.0 \%)$ \\
Practices & $397(88.3 \%)$ & $53(11.7 \%)$ & $450(100.0 \%)$ \\
\hline
\end{tabular}

In this study $94.7 \%$ of the respondents have knowledge on colostrums but $88.3 \%$ of them have practiced it (Table 7).

Table 8: Distribution of the Respondents by Feeding of Pre Lacteal Meal $(\mathrm{n}=450)$

\begin{tabular}{lcc}
\hline Pre-lacteal meal Feeding & Frequency & Percentage \\
\hline Yes & 86 & 19.1 \\
No & 364 & 80.9 \\
\hline Total & $\mathbf{4 5 0}$ & $\mathbf{1 0 0 . 0}$ \\
\hline
\end{tabular}

Only $19.1 \%$ gave pre-lacteal meal to the baby (Table 8 ).

Table 9: Distribution by Initiation of Breast Milk $(n=450)$

\begin{tabular}{lcc}
\hline Initiation of breast milk & Frequency & Percentage \\
\hline Less than $1 \mathrm{hr}$ & 341 & 75.8 \\
1 to $12 \mathrm{hr}$ & 96 & 21.3 \\
13 to $24 \mathrm{hr}$ & 4 & 00.9 \\
More than $24 \mathrm{hr}$ & 9 & 02.0 \\
\hline Total & $\mathbf{4 5 0}$ & $\mathbf{1 0 0 . 0}$ \\
\hline
\end{tabular}

It had been found that $75.8 \%$ of the respondents initiated breast milk in less than 1 hour followed by $21.3 \%$ in $1-12$ hours, $2 \%$ in more than 24 hours and $0.9 \%$ in $13-24$ hours respectively (Table 9).

Table 10: Distribution of the Respondents by Knowledge on Exclusive Breast Feeding $(n=450)$

Knowledge on exclusive breast feeding Frequency Percentage

\begin{tabular}{lcc}
\hline $\begin{array}{l}\text { Knowledge on exclusive } \\
\text { breast feeding }\end{array}$ & Frequency & Percentage \\
\hline Yes & 407 & 90.4 \\
No & 43 & 9.6 \\
\hline Total & $\mathbf{4 5 0}$ & $\mathbf{1 0 0 . 0}$ \\
\hline
\end{tabular}

Majority of the respondents $(90.4 \%)$ had knowledge on exclusive breast feeding and rest of them did not have any knowledge on it (Table 10).

Table 11: Distribution of the Respondents by Duration of Exclusive Breast Feeding in Months $(n=450)$

\begin{tabular}{lcc}
\hline Duration of exclusive breast feeding & Frequency & Percentage \\
\hline Less than 1 month & 39 & 8.7 \\
Less than 3 month & 63 & 14.0 \\
Within 4 - 6 months & 258 & 57.3 \\
Within 7 -- 8 months & 24 & 5.3 \\
Up to 9 months or more & 66 & 14.7 \\
\hline Total & $\mathbf{4 5 0}$ & $\mathbf{1 0 0 . 0}$ \\
\hline
\end{tabular}


It has been explored that $57.3 \%$ of the respondents fed exclusive breast feeding for 4-6 months, $14.7 \%$ for 9 months or more, $14 \%$ for less than 3 months, $8.7 \%$ for less than 1 month and 5.3\% for 7-8 months (Table 11).

Table 12: Distribution of the Respondents by Feeding with Bottle $(n=450)$

\begin{tabular}{lcc}
\hline Feeding with bottle & Frequency & Percentage \\
\hline Yes & 168 & 37.3 \\
No & 282 & 62.7 \\
\hline Total & $\mathbf{4 5 0}$ & $\mathbf{1 0 0 . 0}$ \\
\hline
\end{tabular}

More than $1 / 3^{\text {rd }}(37.3 \%)$ of the respondents fed their baby cow/powder milk with bottle and rest of them did not feed (Table 12).

Table 13: Distribution of the Respondents by Starting Time of Bottle Feeding $(n=450)$

\begin{tabular}{lcc}
\hline Starting time of bottle feeding & Frequency & Percentage \\
\hline within 1 month & 230 & 51.1 \\
within 2 to 3 months & 23 & 5.1 \\
within 4 to 6 months & 42 & 9.3 \\
within 7 to 8 months & 61 & 13.6 \\
within 9 months or more time & 84 & 18.7 \\
\hline Total & $\mathbf{1 0}$ & $\mathbf{2 . 2}$ \\
\hline
\end{tabular}

It is found that more than fifty person $(51.1 \%)$ of the respondents started bottle feeding within 1 month \& 18.7\% in 9 months or thereafter (Table 13).

Table 14: Distribution of the Respondents by Duration of Total Breast Feeding in Months $(n=450)$

\begin{tabular}{lcc}
\hline Duration of total breast feeding & Frequency & Percentage \\
\hline Up to 3 months or less & 22 & 4.7 \\
Within 3 -- 6 months & 93 & 20.6 \\
Within 7 --12 months & 62 & 13.6 \\
Within 13 -- 24 months & 273 & 61.1 \\
\hline Total & $\mathbf{4 5 0}$ & $\mathbf{1 0 0 . 0 0}$ \\
\hline
\end{tabular}

Majority of the respondents (61.1\%) breast fed their baby 13-24 months \& only $4.7 \%$ fed up to 3 months (Table 14 ).

Table 15: Distribution of the Respondents by Frequency of Breast Fed in Last 24 Hours $(n=450)$

\begin{tabular}{lcc}
\hline $\begin{array}{l}\text { Frequency of breast fed } \\
\text { in last } 24 \text { hours }\end{array}$ & Frequency & Percentage \\
\hline 3 times or less & 43 & 9.6 \\
4 to 6 times & 121 & 26.9 \\
7 times or more & 135 & 30.0 \\
Don't know & 151 & 33.6 \\
\hline Total & $\mathbf{4 5 0}$ & $\mathbf{1 0 0 . 0 0}$ \\
\hline
\end{tabular}

It has been found that $30 \%$ of the respondent's breast fed their baby 7 times or more in last 24 hours \& only $9.6 \%$ fed 3 times or less (Table 15).
Table 16: Distribution of the Respondents by Starting Time of Complementary Feeding in Months $(n=450)$

\begin{tabular}{lcc}
\hline Initiation of complementary feeding & Frequency & Percentage \\
\hline Before 6 months & 50 & 11.11 \\
Within 6 to 8 months & 320 & 71.12 \\
Within 9 to 12 months & 58 & 12.89 \\
After 12 months & 22 & 4.88 \\
\hline Total & $\mathbf{4 5 0}$ & $\mathbf{1 0 0 . 0 0}$ \\
\hline
\end{tabular}

In this study $71.12 \%$ of the respondents started complementary feeding in the months of 6-8 months, $11.11 \%$ before 6 months, $12.89 \%$ in $9-12$ months and only $4.88 \%$ started it after 12 months (Table 16).

Table 17: Knowledge of the Respondents on Complementary Feeding $(n=450)$

\begin{tabular}{lcc}
\hline Variables & Frequency & Percentage \\
\hline Complementary feeding Preparation & 301 & 66.9 \\
Complementary feeding & 390 & 86.7 \\
Knowledge on food of grains & 223 & 49.6 \\
Knowledge on milk \& products & 250 & 55.6 \\
Knowledge on food of meat, fish, poultry, liver & 257 & 57.1 \\
Knowledge on food made of eggs & 235 & 52.2 \\
Knowledge on Vit. A richen food & 213 & 47.3 \\
Knowledge on Iron richen products & 227 & 50.4 \\
Knowledge on fruits, vegetables & 204 & 45.3 \\
\hline
\end{tabular}

It is shown that majority of the respondents $(86.7 \%)$ had knowledge on complementary feeding and $13.3 \%$ did not have it. In this study $66.9 \%$ of the respondents had knowledge on preparation of complementary feeding and rest of them did not have it. Out of 450 respondents $49.6 \%$ of the respondents had knowledge on preparation of food by grains and rest of them did not have it. More than half of the respondents $(55.6 \%)$ had knowledge on preparation of food by milk and milk products and rest of them did not have it. Among the all the respondents $57.1 \%$ of the respondents had knowledge on preparation of food by meat, fish, poultry, liver and rest of them did not have. In this study $52.2 \%$ of the respondents had knowledge on preparation of food from eggs and rest of them did not have it. More than half (52.6\%) of the respondents had no knowledge on preparation of food by Vitamin A richen fruits and vegetables and rest of them had it. Half of the respondents had knowledge on preparation of food by Iron richen products and rest of them did not have it. It is found that $54.7 \%$ of the respondents did not have knowledge on preparation of food from fruits, vegetables, leaves and rest of $45.3 \%$ had the knowledge (Table 17). 
Table 18: Distribution of the Respondents by Feeding in Last 24 Hour $(n=450)$

\begin{tabular}{lccccccc}
\hline $\begin{array}{l}\text { Frequency } \\
\text { of } \\
\text { feeding }\end{array}$ & $\begin{array}{c}\text { Grain, roots } \\
\text { and } \\
\text { tubers }\end{array}$ & $\begin{array}{c}\text { Legume, } \\
\text { seeds, pulses } \\
\text { and nuts }\end{array}$ & $\begin{array}{c}\text { Milk \& } \\
\text { Dairy } \\
\text { products }\end{array}$ & $\begin{array}{c}\text { Flash, } \\
\text { meat, } \\
\text { fish }\end{array}$ & $\begin{array}{c}\text { Vit-A richen } \\
\text { fruits/ } \\
\text { vegeta }\end{array}$ & $\begin{array}{c}\text { Iron } \\
\text { richen } \\
\text { food }\end{array}$ & Others \\
\hline No fed & $69(15.3 \%)$ & $90(20.0 \%)$ & $103(22.9 \%)$ & $130(28.9 \%)$ & $107(23.8 \%)$ & $150(33.3 \%)$ & $111(24.7 \%)$ \\
$1-2$ times & $100(22.2 \%)$ & $73(16.2 \%)$ & $87(19.3 \%)$ & $63(14.0 \%)$ & $59(13.1 \%)$ & $45(10.0 \%)$ & $41(9.1 \%)$ \\
$3-4$ times & $110(24.4 \%)$ & $37(8.2 \%)$ & $29(6.4 \%)$ & $28(6.2 \%)$ & $13(2.9 \%)$ & $12(2.7 \%)$ & $12(2.7 \%)$ \\
5-6 times & $25(5.6 \%)$ & $14(3.1 \%)$ & $36(8.0 \%)$ & $15(3.3 \%)$ & $10(2.2 \%)$ & $4(0.9 \%)$ & $2(0.4 \%)$ \\
Did not know & $143(32.4 \%)$ & $236(52.4 \%)$ & $197(43.2 \%)$ & $215(47.5 \%)$ & $262(57.3 \%)$ & $239(52.2 \%)$ & $284(62.2 \%)$ \\
\hline
\end{tabular}

Among the respondents $24.4 \%, 82 \%, 6.4 \%, 6.2 \%$ and less than 3\% fed 3-4 times of grain roots and tubers, legumes, seeds, pulses and nuts, dairy products, flash and Vit. A richen fruits/vegetables, iron rich food and others respectively (Table 18).

\section{Discussion}

Early initiation of breastfeeding, exclusive breastfeeding for six months, and timely introduction of complementary feeding are the key interventions to achieve the Sustainable Development Goal 1 and 4, which address child malnutrition component of the targets and mortality respectively $y^{11-12}$. The present study revealed that $41.6 \%$ of the children belong to group of 13 - 24 months, $36.4 \%$ to $6-12$ months and only $22 \%$ to less than 6 months \& out of 450 children, $51.1 \%$ are female \& $48.9 \%$ are male which correlates with census demography of Bangladesh. $69.3 \%$ of the mothers have only two or less children. $33.3 \%$ of respondents belonged to family income of TK less than $5000 / \&$ only $10.2 \%$ to family income of TK more than 20,000 . It further revealed that $23.1 \%$ of mothers were in $18-20$ years which indicates early motherhood. It further revealed that only $8.4 \%$ of mothers \& $13.6 \%$ of fathers are illiterate, $91.8 \%$ of mothers are housewife \& $33.3 \%$ fathers are farmers respectively.

Initiation of breastfeeding within one hour of birth was more $(75.8 \%)$ than the corresponding national $(24.5 \%)$ figure of the NFHS 3 in India ${ }^{13}$. A study in Ghana reported that $22 \%$ of all neonatal deaths could be prevented if all women could initiate breastfeeding within one hour of delivery ${ }^{14}$. The use of pre lacteal feeding was far less (19.1\%) compared to the corresponding reported by Roy et $\mathrm{al}^{15}$. The corresponding figures were $8 \%$ in rural Bangladesh ${ }^{16}$ and $71 \%$ in urban Bangladesh ${ }^{17}$.

The present study revealed that exclusive breastfeeding less than six months $(57.1 \%)$ which is similar $(58.6 \%)$ to the report of West Bengal of India ${ }^{18}$. The declining rate of exclusive breastfeeding with age was also reported in the NFHS ${ }^{3}$ study in India ${ }^{13,18}$ and by Saha et $\mathrm{al}^{16}$ in Bangladesh and Hop et $\mathrm{al}^{19}$ in Vietnam in longitudinal studies. Several studies showed that partial breastfeeding was associated with increased risk of child morbidity and mortality ${ }^{11,20-21}$. Even introduction of plain water was reported to interfere with breastfeeding ${ }^{22}$.

The proportion of bottle-feeding (37.3\%) in the present study was comparable with results of a study by Wamani et $\mathrm{al}^{23}$; however, less than the reported by Pandey et $\mathrm{al}^{24}$ from rural West Bengal, India. Cousens et $\mathrm{al}^{25}$ found that, when prolonged breastfeeding was accompanied with complementary solid foods, there was a reduction in clinical malnutrition. It is worthwhile to note that the percentage of complementary feeding improved a lot $(93.6 \%)$ at 9 to 11 months of age. Saha et $\mathrm{al}^{16}$ and Hop et $\mathrm{al}^{19}$ have corroborated the findings.

Studies in Malawi revealed that children who were given foods according to the time schedule recommended by the WHO were found to be well-nourished compared to children who received complementary feeding early ${ }^{26}$. A study in Bangladesh documented that the frequency, amount, energy-density, and diversity of food remained important issues in complementary feeding ${ }^{27}$. Factors, such as characteristics of diet or child's appetite, traditional beliefs and practices are known to influence the frequency of complementary feeding ${ }^{23-24,28-29}$. As for inappropriate complementary feeding practices, late introduction, low frequency, and inadequate amount of solid or semi-solid food turned out to be the areas of main thrust. In Bangladesh, infectious diseases, such as diarrhea and acute respiratory infections, are a cause of more than two-thirds of all deaths in children aged less than one year. The importance of breastfeeding in the prevention of infectious diseases during infancy is well-documented. Breast milk provides protection against pathogens by providing antibacterial and antiviral substances that stimulate the infant's immune 
system. Factors that interact with the protective effect of breastfeeding include environmental, cultural and economic characteristics. The protective effect of breastfeeding is most important in populations with high infant mortality, high illiteracy, poor sanitation facilities, poor nutritional status, and generally low economic status. The population of Bangladesh fits all of these criteria. Intervention programs should strive to improve conditions for enhancing current infant feeding recommendations, particularly in low-income conditions like Bangladesh.

\section{Conclusion}

The recommendation from the Global Strategy for Infant and Young Child Feeding Practices, developed by World Health Organization (WHO) in collaboration with United Nations Children's Fund (UNICEF), is that infants should be exclusively breastfed for the first six months of life; after six months, infants should receive nutritionally-adequate and safe complementary foods while continuing to be breastfed for up to two years of age or beyond and make awareness raising initiatives for Infant and Young Child Feeding (IYCF) Practices from GO and NGOs.

\section{References}

1. World Health Organization. Indicators for assessing breastfeeding practices. Geneva: WHO, 1991. J Health Popul Nutr 2008; 26(3): 253-260

2. World Health Organization. Guiding principles for feeding non-breastfed children 6-24 months of age. Geneva: WHO, 2005. Accessed: 5 March 2009; web address: http://w.w.w.who.int/childadolescent health/ documents/ 9241593431 /en/index.html

3. Victora CG, Smith PG, Vaughan JP, Nobre LC, Lombardi C, Teixeira AM, et al. Infant feeding and deaths due to diarrhea: A case-control study. Am J Epidemiol 1989; 129:1032-41

4. Arifeen S, Black RE, Antelman G, Baqui A, Caulfield L, Becker $\mathrm{S}$. Exclusive breastfeeding reduces acute respiratory infections and diarrhea deaths among infants in Dhaka slums. Pediatrics 2001;108:E67

5. Bangladesh Breastfeeding Foundation: protection, promotion and support breastfeeding; Web Address: http:/www.bbf-bd.org/home

6. Women Medical Hospital, Dow University of Health Science and Civil Hospital, Karachi, Pakistan. J Dow Univer Health Sci 2014;8 (1): 21-25

7. National Institute of Child Health Karachi, Pakistan. J Dow Univers Health Sci 2014;8(1):21-25

8. Faruque AJMO, Begum F, Khan N, Mullick MNI. Impact of an education programme on mothers' knowledge on infant and child feeding practices. Bangladesh J Nutration 1992;5(2):1-10

9. Mukuria AG, Kothari MT, Abderrahim N. Infant and Young
Child Feeding Updates. Calverton, Maryland, USA: ORC Macro; 2006. [Last Accessed on: 2012 Apr 29]. [Available http://w.w.w.measuredhs.com/pubs/pdf/NUTI/NUTI.pdf]

10. hutta ZA, Ahmed T, Black RE, Cousens S, Dewey K, Giugliani $\mathrm{E}$, et al. What works? Interventions for maternal and child under nutrition and survival. Lancet 2008; 371:417-40

11. Dadhich JP, Agarwal RK. Mainstreaming early and exclusive breastfeeding for improving child survival. Indian Pediatr 2009;46:11-7

12. International Institute for Population Sciences. National family health survey (NFHS 3), 2005-06: India.V-I. Mumbai: International Institute for Population Sciences; 2007. p. 540

13. Edmond KM, Zandoh C, Quigley MA, Amenga-Etego S, Owusu-Agyei S, Kirkwood BR. Delayed breastfeeding initiation increases risk of neonatal mortality. Pediatrics. 2006;117: e380-6

14. Edmond KM, Kirkwood BR, Amenga-Etegos S, Owusu-Agyei S, Hurt LS. Effect of early infant feeding practices on infection-specific neonatal mortality: an investigation of the causal links with observational data from rural Ghana. Am J Clin Nutr. 2007; 86:1126-31

15. Roy S, Dasgupta A, Pal B. Feeding practices of children in an urban slum of Kolkata. Indian J Community Med. 2009; 34:362-3 16. Hassan MQ, Hannan A, Kabir ARML, Barua PC, Rahman AKMF, Rahman A, et al. Infant and young child feeding practices in urban areas of Bangladesh (abstract) Dhaka: International Centre for Diarrhoeal Disease Research, Bangladesh; 2006. P-20

17. International Institute for Population Sciences . National family health survey (NFHS 3), 2005-06: India. V-II. Mumbai: International Institute for Population Sciences; 2007. p. 168

18. Saha KK, Frongillo EA, Alam DS, Ariffen SE, Persson LA, Rasmussen KM. Appropriate infant feeding practices result in better growth of infants and young children in rural Bangladesh. Am J Clin Nutr. 2008; 87:1852-9

19. Hop LT, Gross R, Giay T, Sastroamidjojo S, Schultink W, Lang NT. Premature complementary feeding is associated with poorer growth of Vietnamese children. J Nutr. 2000;130: 2683-90

20. Black RE, Morris SS, Bryce J. Where and why are 10 million children dying every year? Lancet. 2003; 361:2226-34

21. Jones G, Steketee RW, Black RE, Bhutta ZA, Morris SS, Bellagio Child Survival Study Group How many child deaths can we prevent this year? Lancet. 2003; 362:65-71

22. Sachdev HP, Krishna J, Puri RK, Satyanarayana L, Kumar S. Water supplementation in exclusively breastfed infants during summer in the tropics. Lancet. 1991; 337:929-33

23. Wamani H, Astrøm AN, Peterson S, Tylleskär T, Tumwine JK. Infant and young child feeding in western Uganda: knowledge, practices and socio-economic correlates. J Trop Pediatr. 2005; 51:356-61

24. Pandey GK, Hazra S, Vajpayee A, Chatterjee P. Breastfeeding indicators from a rural community in West Bengal. Ind J Public Health. 1997; 41:71-4

25. Cousens S, Nacro B, Curtis V, Kanki B, Tall F, Traore E, et al. Prolonged breast-feeding: no association with increased risk of clinical malnutrition in young children in Burkina Faso. Bull World Health Organ. 1993; 71:713-22

26. Madise NJ, Mpoma MO. Child malnutrition and feeding practices in Malawi. Food Nutr Bull. 1997; 18:190-201

27. Jumaan AO, Serdula MK, Williamson DF, Dibley MJ, Binkin NJ, Boring JJ. Feeding practices and growth in Yemeni children. J Trop Pediatr. 1989; 35:82-6

28. Kimmons JE, Dewey KG, Haque E, Chakraborty J, Osendarp SJ, Brown KH. Low nutrient intakes among infants in rural Bangladesh are attributable to low intake and micronutrient 